\title{
GESTÃO AMBIENTAL, LEGISLAÇÃO E OS RECURSOS HÍDRICOS NA CIDADE DE FORTALEZA (CE), BRASIL
}

ENVIRONMENTAL MANAGEMENT, LEGISLATION AND WATER RESOURCES IN FORTALEZA (CE), BRAZIL

\section{Francisca Dalila}

\section{Menezes Vasconcelos}

Engenheira ambiental e sanitarista e mestre em Ciências Ambientais.

Doutoranda em Engenharia Civil, área de concentração em Saneamento Ambiental, pela Universidade Federal do Ceará (UFC) - Fortaleza (CE), Brasil.

\section{Francisco Suetônio Mota} Professor titular do Departamento de Engenharia Hidráulica e Ambiental, da UFC - Fortaleza (CE), Brasil.

\section{Endereço para correspondência:}

Francisca Dalila Menezes

Vasconcelos - Departamento de Engenharia Hidráulica e Ambiental - Campus do Pici, Bloco 713 - CEP: 60455.760 - Fortaleza (CE), Brasil Email: menezes.dalila@gmail.com

Recebido em: 30/10/2019

Aceito em: 07/02/2020

\section{RESUMO}

Este trabalho discute a importância da gestão ambiental e da legislação de controle urbano para a proteção dos recursos hídricos. Destaca, também, a importância da lei de uso do solo para a conservação ambiental, devendo o zoneamento urbano considerar as características do ambiente natural. É feita uma avaliação da legislação de uso e ocupação do solo de Fortaleza (CE), constatando-se que ela nem sempre segue as exigências do código florestal do Brasil, no que concerne às Áreas de Preservação Permanente (APP). A última alteração da legislação municipal (lei complementar no 250/2018) resultou na redução de $961.185,34 \mathrm{~m}^{2}$ das APP às margens dos recursos hídricos de Fortaleza (CE). Utilizando a sobreposição de mapas e visitas de campo, foram identificadas as alterações ocorridas nas APP em duas bacias hidrográficas da cidade de Fortaleza (CE), Brasil, ocorrendo reduções após a lei complementar $n$ 으 250/2018.

Palavras-chave: áreas de preservação permanente; áreas ribeirinhas; uso do solo; controle urbano; zoneamento urbano.

\section{ABSTRACT}

This paper discusses the importance of environmental management and urban control legislation for the protection of water resources. It also highlights the importance of land use law for environmental conservation and that urban zoning should consider the natural environment characteristics. It was evaluated the Fortaleza (CE) legislation about land use and it was noted that it does not observe Forest Code of Brazil requirements with regard to Permanent Preservation Areas (PPA). The latest legislation amendment (Complementary Law No. 250/2018) resulted in a reduction of $961,185.34 \mathrm{~m}^{2}$ of permanent preservation areas on water resources margins in Fortaleza, Ceará. Using map overlays and field visits, the changes occurred in preservation areas in two river basins of the city of Fortaleza, Ceará, Brazil, were identified. After Complementary Law No. 250/2018, there were reductions in the areas of permanent preservation in the two river basins.

Keywords: permanent preservation areas; riparian areas; land use; urban control; urban zoning. 


\section{INTRODUÇÃO}

Os recursos hídricos constituem a base que sustenta todo o sistema de vida da Terra. Especialmente para bacias severamente afetadas pela crise hídrica, o manejo integrado dos recursos hídricos é importante para a reabilitação dos ecossistemas aquáticos, suas funções e para a garantia do desenvolvimento sustentável das bacias hidrográficas (ZHANG; JIN; YU, 2018).

O crescimento da população urbana, no Brasil e no mundo, tem resultado em alterações ambientais significativas, incluindo, entre elas, as modificações nos recursos hídricos tanto em termos de qualidade como de quantidade.

Por outro lado, os recursos hídricos desempenham importante papel na condução da evolução urbana. A água é um elemento crítico para a vida sustentável em áreas urbanas, nas quais as questões relacionadas aos recursos hídricos serão cada vez mais importantes no futuro (KAUSHAL et al., 2015).

Os corpos de água são ecossistemas ecológicos cultural e economicamente importantes que fornecem muitos serviços valiosos à humanidade. No entanto, à medida que as atividades humanas se intensificam (por exemplo, o aquecimento global, o uso da terra, as mudanças na cobertura vegetal, a explosão populacional e outros fatores antropogênicos), ocorrem alterações na quantidade e na qualidade da água, que exigem soluções desafiadoras (WANG; HO; LU, 2019).

A expansão mundial das áreas urbanas tem resultado em marcadas alterações nos processos naturais, na qualidade ambiental e no consumo dos recursos naturais. O espaço urbano tem influência na infiltração e na evapotranspiração. As superfícies impermeáveis tornam mais intenso o processo de escoamento superficial da água. Nas áreas urbanas são produzidos poluentes que impactam a qualidade da água, em que novos contaminantes continuam a representar desafios para seu monitoramento e tratamento (MCGRANE, 2016).

Segundo Sun e Caldwell (2015), o aumento da população e o desenvolvimento constituem a maior ameaça ao suprimento de água de boa qualidade. Essa ameaça é aumentada em áreas com secas periódicas e com maiores faixas de temperatura e precipitação associadas às mudanças climáticas causadas pela ação humana. Uma área urbanizada é mais suscetível aos impactos negativos das mudanças climáticas, por causa da perda da capacidade de proteção dos ecossistemas naturais.

Para o equacionamento desta questão, é fundamental uma efetiva modificação na relação entre as políticas urbanas e de recursos hídricos, visando a integração e a cooperação entre esses dois sistemas, sobretudo quando se trata de bacias intensamente urbanizadas, cuja gestão está intimamente ligada aos processos de uso e ocupação do solo urbano (GASPAR; KLINK, 2008).

$O$ atual modelo de desenvolvimento observado, principalmente nas cidades, com a crescente demanda por recursos naturais e espaço físico, tem ocorrido com áreas que deveriam servir como suporte à preservação ambiental, como as margens de córregos e rios (APP), sendo ocupadas de forma desordenada e sem planejamento, o que resulta em diversos problemas ambientais urbanos como inundações, proliferação de doenças veiculadas pela água, despejos de efluentes sanitários nos corpos hídricos, deslizamentos de terra, enchentes, aumento do escoamento superficial, entre outros (SILVA; SANTOS; GALDINO, 2016).

As cidades precisam de água para diversas atividades e, ao mesmo tempo, geram resíduos resultantes dos diversos usos, os quais têm como destino os recursos hídricos, muitas vezes, poluindo-os.

A expansão das áreas urbanas tem sido feita à custa de desmatamentos, alterações no relevo, impermeabilização do solo, aterramento de cursos de água e lagoas, retiradas excessivas de águas superficiais e subterrâneas, entre outras intervenções as quais resultam na degradação dos recursos hídricos.

As diferentes fontes de poluição em um ambiente urbano, desde o escoamento das águas pluviais até o lançamento de efluentes de estações de tratamento de esgotos e a poluição industrial, entre outras, causam impactos sobre os recursos hídricos. Ao mesmo tempo, a capacidade suporte natural de corpos hídricos, pântanos e aquíferos é comprometida por meio da implantação do sistema viário e da impermeabilização do solo, resultando na diminuição da infiltração da água e no aumentando do escoamento das águas pluviais. O impacto cumulativo dessas e de outras atividades ainda não é totalmente compreendido (RIEMANN et al., 2017). 
A qualidade das zonas ribeirinhas está inversamente relacionada ao grau de urbanização das áreas adjacentes, observando-se que os usos da terra com maior cobertura florestal garantem uma condição menos degradada e maior diversidade de espécies (DÍAZ-PASCACIO et al., 2018).

Uma das principais ferramentas de proteção dos recursos hídricos, no Brasil, é o Código Florestal (Lei Federal no. 4.771, de 25 de maio de 2012), que regulamenta a definição de APPs para as faixas marginais dos corpos de água (BRASIL, 2012).

Segundo Campagnolo et al. (2017), o Código Florestal brasileiro, em todas suas versões, tem como essência a manutenção da qualidade de vida de toda a sociedade brasileira, pois entende que a conservação dos ecossistemas e a proteção dos recursos naturais são de interesse comum. No entanto, ressaltam que o Novo Código Florestal carece de muitos estudos técnicos para que sua efetividade seja confirmada, bem como os benefícios propostos.

Os recursos hídricos não podem ser considerados como ambientes isolados, mas associados aos outros componentes do meio como um todo. Uma alteração em um dos meios pode causar modificações nos am- bientes aquáticos, tanto sob os aspectos quantitativos como qualitativos (MOTA, 2019).

Os recursos hídricos têm grande interação com os demais componentes de suas áreas adjacentes que compreendem a bacia hidrográfica. Assim, a administração dos recursos hídricos deve integrar uma gestão ambiental mais ampla, que compreenda toda a bacia hidrográfica.

As ações de gestão ambiental de determinada área têm grande repercussão nos recursos hídricos que a integram.

A qualidade e a quantidade de um recurso hídrico dependem dos usos da água e das atividades desenvolvidas na bacia hidrográfica. Para que se garanta o uso adequado do solo e da água, é necessária uma legislação com enfoque no controle ambiental.

Este trabalho teve como objetivo destacar a importância da gestão e da legislação ambiental para a proteção dos recursos hídricos e realizar, como estudo de caso, utilizando a sobreposição de mapas e visitas de campo, uma avaliação da legislação de uso e ocupação do solo de Fortaleza (CE), Brasil, comparando com a legislação federal em vigor

\section{MATERIAIS E MÉTODOS}

Este trabalho foi desenvolvido em duas etapas: na primeira são discutidas as ferramentas de gestão ambiental e de legislação de controle ambiental, com ênfase para a proteção dos recursos hídricos; na segunda, faz-se uma análise da situação das APPs de recursos hídricos urbanos, no contexto da legislação municipal da cidade de Fortaleza.

O município de Fortaleza é composto por quatro Bacias Hidrográficas: Cocó, Maranguapinho/Ceará, Pacoti e Vertente Marítima. Neste trabalho, foram avaliadas as alterações provocadas pelas mudanças na legislação nas Bacias do Rio Cocó e do Rio Maranguapinho.

Os métodos adotados foram: pesquisa bibliográfica, pesquisa documental, sobreposição de mapas e visitas de campo.

Inicialmente, realizou-se uma revisão bibliográfica sobre o tema central. Posteriormente, foram estudadas e discutidas as legislações pertinentes por meio de pesquisa documental.
Sá-Silva, Almeida e Guindani (2009) apontam a principal diferença entre a pesquisa bibliográfica e documental, afirmando que a bibliográfica remete para as contribuições de diferentes autores sobre o tema, como as fontes secundárias, enquanto a documental recorre aos materiais que ainda não receberam tratamento analítico, ou seja, as fontes primárias.

O método de construção e sobreposição de mapas promove a integração de informações e permite a visualização espacial mais didática dos dados. Segundo Cremonez et al. (2014), essa metodologia consiste na montagem de uma série de mapas temáticos, no qual cada mapa indica uma característica cultural, social e física que reflete um impacto.

Os mapas apresentados neste trabalho foram construídos por meio do Sistema de Informações Geográficas (SIG), software QGIS na versão 2.14.16 (Essen), que permite a edição de mapas dos arquivos em formato KML e Shapfile. Os arquivos utilizados para elaboração 
dos mapas encontram-se disponíveis nos sites da Prefeitura de Fortaleza (PMF), na plataforma Fortaleza em
Mapas, no Infocidades, ano 2019 (https://mapas.fortaleza.ce.gov.br).

\section{GESTÃO AMBIENTAL URBANA E OS RECURSOS HÍDRICOS}

De acordo com Philippi Jr. e Bruna (2013), gestão ambiental é o ato de administrar, de dirigir ou reger os ecossistemas naturais e sociais em que se insere o homem, individual e socialmente, em um processo de interaçao entre as atividades que exerce, buscando a preservação dos recursos naturais e das características essenciais do entorno, de acordo com padrões de qualidade. Os objetivos últimos são estabelecer, recuperar ou manter o equilíbrio entre natureza e homem.

Mota (2016) enumera as seguintes atividades de gestão ambiental: caracterização e valoração ambiental; estudos de impacto ambiental; licenciamento ambiental; auditoria ambiental; análises de riscos; manejo de recursos ambientais; planejamento ambiental / zoneamento ambiental; gestão de bacias hidrográficas; gestão de áreas de valor ambiental / unidades de conservação; gestão de resíduos; gestão ambiental em empresas / ISO 14000; legislação ambiental; educação ambiental; outras atividades visando a conservação ambiental.

Gestão ambiental urbana é definida por Nolasco e Silva Filho (2010) como o conjunto de rotinas e procedimentos que permite uma organização ou comunidade urbana administrar adequadamente as relações entre suas atividades humanas e o ambiente que as abriga, atentando para as expectativas das partes interessadas com objetivo de atenuar ou anular os efeitos negativos sobre os ecossistemas e a qualidade de vida, advindos dessas atividades.

De acordo com Global Water Partnership (2017), gestão integrada de recursos hídricos é o processo coordenado de desenvolvimento e gestão da água, solo e recursos relacionados, com o objetivo de maximizar o bem-estar econômico e social de forma equitativa, sem comprometer a sustentabilidade de ecossistemas vitais nem o meio ambiente. A gestão deve ter como objetivo o uso equânime, eficiente e sustentável da água, considerando que é um recurso natural, parte integrante de um ecossistema, um bem social e econômico, cujas quantidade e qualidade determinam a sua utilização.
Segundo Kumar, Kumar e Khosla (2016), a gestão dos recursos hídricos deve constituir um conjunto de medidas, regras operacionais e incentivos (economia, regulação, judicial, social) aplicados à água e aos recursos terrestres a ela associados, por meio de um arranjo institucional envolvendo entidades relacionadas à água, ou não, públicas e privadas, e suas regras e regulamentos.

A gestão de recursos hídricos deve estar associada à gestão ambiental como um todo, compreendendo os outros componentes do meio físico, solo e ar, do meio biótico, fauna e flora, e do meio antrópico.

Dois instrumentos de gestão são fundamentais para a proteção dos recursos hídricos: o Plano de Bacia Hidrográfica e o Plano Diretor de Desenvolvimento do Município.

De acordo com a Política Nacional de Recursos Hídricos, estabelecida pela Lei no 9.433, de 8 de janeiro de 1997 (BRASIL, 1997), os Planos de Recursos Hídricos são planos diretores que visam fundamentar e orientar a implementação da Política Nacional de Recursos Hídricos e o gerenciamento dos recursos hídricos. A referida lei considera a bacia hidrográfica como a unidade territorial para implementação da Política Nacional de Recursos Hídricos e atuação do Sistema Nacional de Gerenciamento de Recursos Hídricos.

O Plano de Bacia Hidrográfica, instrumento central de articulação entre o planejamento e a gestão, tem como objetivo geral definir ações de gestão, programas, projetos, obras e investimentos prioritários para esse território, em um contexto que inclua os órgãos governamentais, a sociedade civil, os usuários e as diferentes instituições que participam do gerenciamento dos recursos hídricos. Tal plano também deve levar em consideração todos os demais programas, projetos e estudos que incorporem a proteção dos recursos hídricos na área de abrangência das respectivas bacias hidrográficas, articulando-se com os planejamentos municipais, setoriais e regionais existentes (PERES; SILVA, 2013).

Em nível de planejamento municipal, ressalta-se o Plano Diretor, que, de acordo com a Constituição Federal de 1988 (BRASIL, 1988), é o instrumento básico da polí- 
tica de desenvolvimento e da expansão urbana, devendo ser aprovado pela Câmara Municipal e obrigatório para cidades com mais de vinte mil habitantes.

Conforme Pizella (2015), o Plano Diretor de uso e ocupação do solo constitui o principal instrumento de gestão territorial e municipal, definindo os parâmetros para o cumprimento da função social, ambiental e econômica da propriedade. Nesse sentido, os municípios possuem grande responsabilidade na proteção dos recursos hídricos, e, sem seu apoio, não é possível integrar a gestão territorial e hídrica no âmbito da bacia hidrográfica.

Ressalta-se que os limites das bacias hidrográficas quase sempre não coincidem com os dos territórios municipais, o que constitui uma dificuldade para a implementação das políticas de proteção dos recursos hídricos. Carneiro, Cardoso e Azevedo (2008) levantam a questão de como relacionar a gestão de recursos hídricos por bacias hidrográficas e a gestão do território municipal, ou seja, como a questão do uso do solo deve se inserir nos planos de bacia hidrográfica e como a gestão dos recursos hídricos se inserir nos planos diretores municipais.

Pizella (2015) destaca a necessidade de uma participação mais expressiva do município no Comitê de Bacia, com a qual é possível que as formas de ocupação e uso do solo municipal sejam consideradas no momento de elaboração e execução dos Planos de Bacia. Assim, a gestão dos recursos hídricos pode se dar integradamente.

A integração entre os Planos de Bacia Hidrográfica e os Planos Diretores de Desenvolvimento Urbano municipais é indispensável para que sejam propostas, em ambos, medidas integradas e complementares visando à proteção dos recursos hídricos.

Além do Plano de Gestão de Bacia Hidrográfica e do Plano Diretor de Desenvolvimento do Município, outros instrumentos de gestão ambiental são importantes para a gestão ambiental dos recursos hídricos.

Entre outras atividades da gestão ambiental, podem ser destacadas as que têm maior relação com a gestão dos recursos hídricos urbanos: manejo de outros recursos ambientais - solo, ar, meio biótico, meio antrópico; gestão de áreas de valor ambiental - encostas, áreas de preservação permanente, áreas de recarga de aquíferos, áreas de solos suscetíveis à erosão, áreas de amortecimento de cheias, unidades de conservação, entre outras; gestão de resíduos sólidos, líquidos e gasosos; legislação ambiental; educação ambiental.

Palavizini (2012) ressalta que deve ser concebido e realizado um processo de avaliação complexa permanente, que contemple todas as etapas do planejamento e da gestão, o qual deve prever indicadores e meios de verificação de processos, resultados e impactos.

\section{LEGISLACÃO E OS RECURSOS HÍDRICOS}

Ferramentas legais e administrativas são requeridas para permitir e aplicar a gestão ambiental da água em todos os níveis. Uma estrutura de administração para a gestão ambiental dos recursos hídricos é necessária para apoiar os seus objetivos e deve ser entendida e implementada por todas as partes interessadas (AITHER, 2018).

O conjunto de órgãos e colegiados federais, estaduais e municipais, responsáveis pela concepção e implementação das ações de gestão de recursos hídricos, constituem a estrutura administrativa para garantir o uso adequado da água.

Como ferramentas legais, incluem-se leis, decretos, resoluções, normas, portarias e outros documentos em nível federal, estadual e municipal, que garantem a conservação dos recursos hídricos.
Duas leis federais são importantes: a Lei no 6.938, de 31 de agosto de 1981, que estabeleceu a Política Nacional do Meio Ambiente (BRASIL, 1981), e a Lei no 9.433, de 8 de janeiro de 1997, que instituiu a Política Nacional de Recursos Hídricos.

A lei da Política Nacional do Meio Ambiente inclui como um dos seus princípios a racionalização do uso do solo, do subsolo, da água e do ar. A lei referida considera como um dos seus instrumentos o zoneamento ambiental.

Entre os fundamentos da Política Nacional de Recursos Hídricos, encontram-se: a gestão dos recursos hídricos deve sempre proporcionar o uso múltiplo das águas; a bacia hidrográfica é a unidade territorial para implementação da política; a gestão dos recursos hídricos 
deve ser descentralizada e contar com a participação do poder público, dos usuários e das comunidades.

De acordo com a Lei no 9.433/97, constituem diretrizes gerais de ação para implementação da Política Nacional de Recursos Hídricos: a gestão sistemática dos recursos hídricos, sem dissociação dos aspectos de quantidade e qualidade; a adequação da gestão de recursos hídricos às diversidades físicas, bióticas, demográficas, econômicas, sociais e culturais das diversas regiões do País; a integração da gestão de recursos hídricos com a gestão ambiental; a articulação do planejamento de recursos hídricos com o dos setores usuários e com os planejamentos regional, estadual e nacional; a articulação da gestão de recursos hídricos com a do uso do solo; a integração da gestão das bacias hidrográficas com a dos sistemas estuarinos e zonas costeiras.

Conforme disposto na lei da Política Nacional de Recursos Hídricos tem que haver a articulação entre a gestão de recursos com a do uso do solo. Assim, os controles do uso e da ocupação de uma bacia hidrográfica devem ser disciplinados, de forma a garantir a proteção dos recursos hídricos que a integram.

As normas de proteção às florestas e recursos hídricos brasileiros são fundamentadas na Lei no 4, de 1965, com atualizações baseadas na Lei no 7.803 , de 1989, e Medida Provisória no 2.166-67, de 2001, responsáveis pelo atual código florestal (ZANDER et al., 2010).

A preservação das margens dos recursos hídricos é exigida pelo Código Florestal - Lei no 4.771, de 25 de maio de 2012. Essa lei dispõe sobre a vegetação nativa e considera como APP: as faixas marginais de qualquer curso de água natural perene e intermitente, excluídos os efêmeros, desde a borda da calha do leito regular; as áreas no entorno dos lagos e lagoas naturais; as áreas no entorno dos reservatórios de águas artificiais, decorrentes de barramento ou represamento de cursos de águas naturais; as áreas no entorno das nascentes e dos olhos de água perenes.

A preservação das áreas situadas nas margens dos corpos hídricos, embora tenha como objetivo principal proteger a vegetação, constitui importante medida de proteção da água. De acordo com Kusler (2016), as áreas situadas às margens de recursos hídricos constituem uma variedade de funções e valores, como indicado a seguir: contribuem para o controle de inun- dações, armazenando e liberando lentamente a água; reduzem a formação de ondas antes de chegar à costa, diminuindo a força das águas; constituem áreas de recarga e descarga de águas subterrânea; contribuem para reduzir a erosão do solo; constituem áreas com vegetação natural; previnem a poluição dos corpos hídricos; constituem habitat para peixes e mariscos; constituem habitat para anfíbios, répteis, mamíferos e insetos; formam habitat para aves aquáticas; constituem habitat para diversas espécies de aves; constituem habitat para animais e vegetais ameaçados de extinção; contribuem para a retenção de carbono e a consequente redução das mudanças climáticas; têm influência no microclima, evitando o aumento da temperatura; podem ser usadas como áreas de recreação e para práticas de ecoturismo; podem proporcionar oportunidades para experiências históricas, arqueológicas, patrimoniais e estéticas; podem constituir áreas para realização de atividades de educação ambiental; podem ser utilizadas como áreas para o desenvolvimento de pesquisas científicas.

O disciplinamento do uso do solo é competência do poder público municipal, o qual, conforme a Constituição do Brasil, é responsável pela política de desenvolvimento urbano, que tem por objetivo ordenar o pleno desenvolvimento das funções sociais da cidade e garantir o bem-estar de seus habitantes.

Os instrumentos das políticas urbanísticas municipais estão fixados nos termos do artigo 30, inciso VIII, da Constituição Federal, no qual dispõe à competência dos municípios promover, no que couber, adequado ordenamento territorial, mediante planejamento e controle do uso, do parcelamento e da ocupação do solo urbano (apud SANTOS, 2011).

Os dispositivos constitucionais foram regulamentados pela Lei no 10.257, de 10 de julho de 2001 (Estatuto da Cidade) (BRASIL, 2001), que estabelece normas de ordem pública e interesse social que regulam o uso da propriedade urbana em prol do bem coletivo, da segurança e do bem-estar dos cidadãos, bem como do equilíbrio ambiental.

O Estatuto da Cidade inclui entre os seus instrumentos o planejamento municipal, em especial: plano diretor; disciplina do parcelamento, do uso e da ocupação do solo; zoneamento ambiental; instituição de unidades de conservação; instituição de zonas especiais de interesse social. 
Outra lei federal relacionada ao uso do solo urbano é o Estatuto da Metrópole - Lei no 13.089, de 12 de junho de 2006, alterada pela Lei no 13.683 , de 19 de junho de 2018. A referida lei estabelece diretrizes gerais para o planejamento, a gestão e a execução das funções públicas de interesse comum em regiões metropolitanas e em aglomerações urbanas instituídas pelos estados, normas gerais sobre o plano de desenvolvimento urbano integrado e outros instrumentos de governança interfederativa, e critérios para o apoio da União às ações que envolvam governança interfederativa no campo do desenvolvimento urbano (BRASIL, 2018).

A possibilidade de se alcançar uma sustentável gestão de recursos hídricos deve, necessariamente, passar por uma clara articulação com o planejamento do uso do solo. O que se observa no Brasil, entretanto, é uma desarticulação entre os instrumentos de gestão de recursos e os de planejamento do uso do solo, refletindo, possivelmente na ausência de legitimidade do planejamento e da legislação urbana nas cidades brasileiras, marcada por um alto grau de informalidade, e mesmo de ilegalidade, na ocupação do solo (CARNEIRO; MIGUEZ, 2012).

Dois instrumentos legais municipais importantes para o controle do uso e ocupação de áreas urbanas são: a Lei de Uso e Ocupação do Solo e a Lei do Parcelamento do Solo. O primeiro define os parâmetros norteadores da ocupação do solo urbano, incluindo o zoneamento, e constitui um importante instrumento para ordenar o desenvolvimento da cidade e garantir a proteção dos recursos hídricos.

Em uma lei de uso do solo elaborada, visando à conservação ambiental, o zoneamento da cidade deve considerar as características do ambiente natural e deve ser proposto visando a proteção de áreas especiais (ou potencialmente frágeis) como: corpos hídricos e suas planícies de inundações, encostas, áreas de recarga de aquíferos, áreas de amortecimento de cheias, dunas, manguezais, entre outras, cuja ocupação inadequada pode prejudicar os recursos hídricos.

Existem duas formas de proteger uma propriedade: por meio de sua desapropriação, transferindo-a para o domínio público, ou pela limitação de usos, restringindo-se sua ocupação. A Lei de Uso e Ocupação do solo é o meio legal de definir os usos e restrições de ocupação de uma área.
$\mathrm{Na}$ definição do zoneamento de uma área urbana podem ser estabelecidas: áreas a serem preservadas (de acordo com a legislação vigente); áreas com ocupação restrita (áreas potencialmente frágeis); e áreas a serem ocupadas com maior intensidade. No estabelecimento dessas áreas devem ser consideradas as características do ambiente, definindo-se menor ocupação para as áreas de valor ambiental.

As áreas que devem ter baixas taxas de ocupação, garantindo grandes áreas permeáveis com vegetação, são: áreas adjacentes às faixas de preservação de recursos hídricos; encostas (o Código Florestal considera como de preservação permanente terrenos com declividade igual ou superior a 450; áreas com inclinação entre 25 e 45o são consideradas como de uso restrito); áreas de recarga de aquíferos; áreas alagáveis / de amortecimento de cheias; áreas de solos suscetíveis à erosão; estuários; manguezais; apicuns e salgados; dunas (eram consideradas como de preservação permanente na versão anterior do Código Florestal).

Também deve ser considerada a existência, ou não, de infraestrutura sanitária. Em áreas onde não existem redes coletoras de esgotos não devem ser permitidas atividades que resultem na geração de grandes vazões de águas residuárias, pois não será possível a adoção de soluções individuais tipo fossa / sumidouro (ou valas de infiltração).

Para a proteção dos recursos hídricos, deve ser definida uma faixa de uso com baixa taxa de ocupação, adjacente à faixa de preservação exigida pelo Código Florestal. Mota (2019) propõe que sejam estabelecidas duas faixas:

- APP às margens dos corpos de água, definida no Código Florestal;

- Faixa de proteção adjacente à área de preservação permanente a ser utilizada com baixas taxas de ocupação, de modo que seja garantida a proteção de grande parte da vegetação, a infiltração da água e o escoamento adequado das águas superficiais.

Nas áreas adjacentes à faixa de preservação permanente somente devem ser permitidos usos como: parques, áreas de lazer, unidades de conservação de uso sustentável, residencial unifamiliar ou outro uso urba- 
no, desde que seja garantida uma área permeável no mínimo igual a $50 \%$ da área do lote.

Na Figura 1, apresenta-se uma proposta de uso e ocupação às margens de um curso de água, em que foram adotadas algumas medidas visando à proteção do corpo hídrico: faixa de preservação permanente às margens do curso de água; na faixa adjacente à área de preservação permanente foram propostos os usos residenciais unifamiliares com baixa e média densidades, em função do afastamento para o corpo hídrico.

Outro exemplo de ocupação às margens de um curso de água está apresentado na Figura 2, observando-se uma área de lazer adjacente à faixa de preservação permanente.
O controle do parcelamento do solo para fins urbanos é um dos itens de maior relevância no que se refere ao ordenamento da cidade, principalmente na organização espacial de novas áreas urbanas. Tem como objetivo garantir que a expansão física dos municípios obedeça às regras e normas de cunho técnico e jurídico, promovendo a distribuição equilibrada de atividades e pessoas no município, estimulando seu desenvolvimento (GOVERNO DO ESPÍRITO SANTO, 2006).

A Lei Federal no 6.766, de 19 de dezembro de 1979, modificada parcialmente pela Lei no 9.785, de 29 de janeiro de 1999, dispõe sobre o Parcelamento do solo urbano, e expressa em seu texto requisitos urbanísticos que objetivam melhor ordenamento das novas áreas urbanas dos municípios brasileiros (GOVERNO DO ESPÍRITO SANTO, 2006).

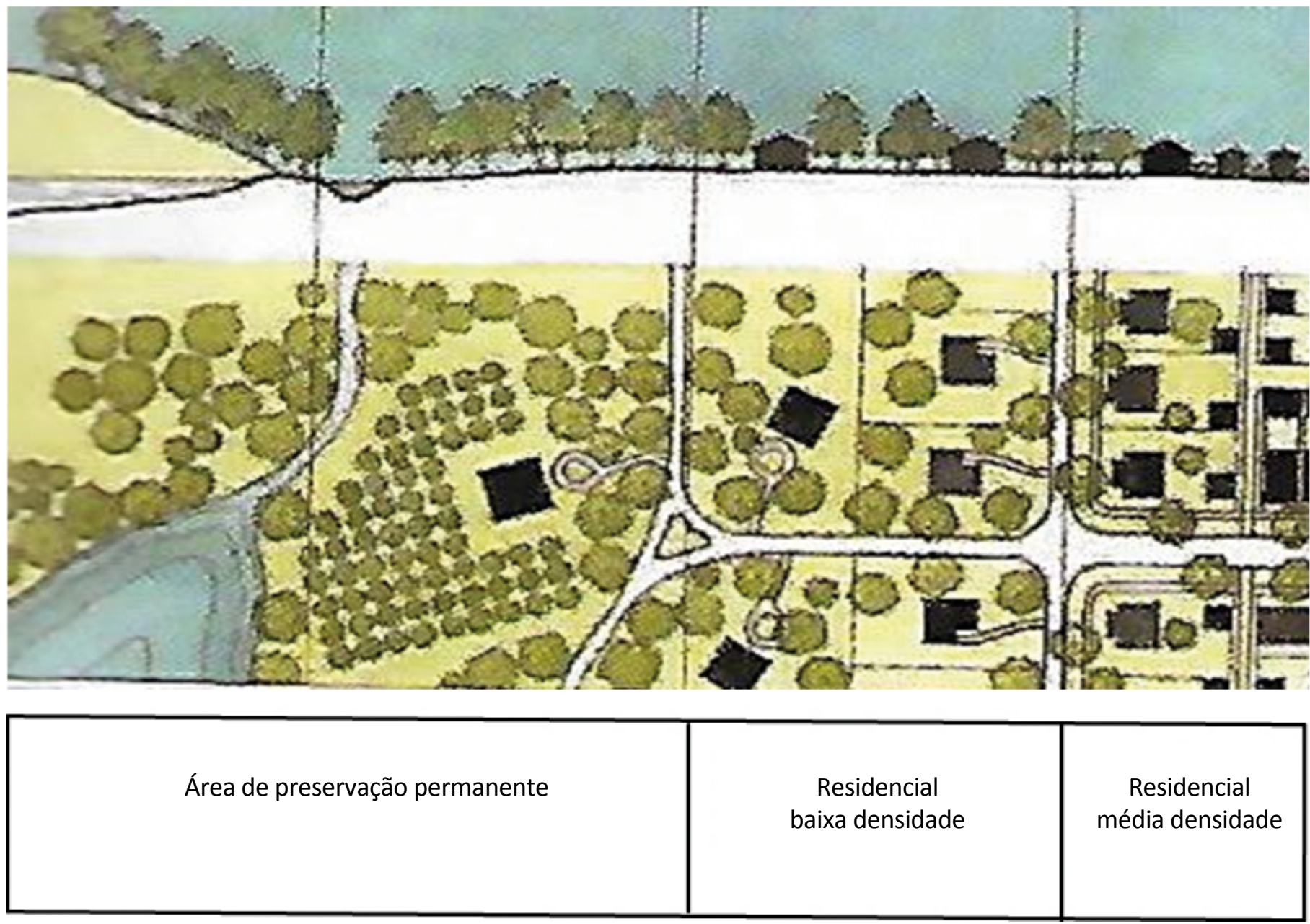

Fonte: adaptado de Randolph (2011).

Figura 1 - Exemplo de ocupação às margens de um curso de água. 
Com o advento do Estatuto da Cidade (Lei no 10.257/01), a disciplina do parcelamento do solo passa a compor o rol de instrumentos que devem ser utilizados para atender aos seus fins. Assim, sendo instrumento útil à execução da política urbana, nenhum parcelamento do solo deverá ser realizado de forma a contrariar as diretrizes insertas nos termos do art. 2으. também da aludida lei federal (MPSC, 2010). O art. 2ㅇ da Lei $n$ o 10.257/01 estabelece que a política urbana tem por objetivo ordenar o pleno desenvolvimento das funções sociais da cidade e da propriedade urbana.

Cabe aos municípios elaborarem a Lei de Parcelamento do Solo, também conhecida como Lei de Loteamentos. Esta lei é um valioso instrumento para o controle da ocupação de áreas urbanas, a qual pode estabelecer exigências visando garantir o escoamento e a infiltração da água em determinada gleba urbana e o seu parcelamento.

Segundo Mota (2019), o melhor projeto de parcelamento é aquele cuja distribuição das vias públicas e dos lotes considera a topografia do terreno e os caminhos naturais de escoamento das águas; que preserva as áreas marginais aos recursos hídricos; que protege áreas de valor ecológico; que prevê lotes maiores e com menor ocupação para as áreas ambientais especiais, tais como áreas adjacentes à faixa de preservação, locais com vegetação, encostas, áreas de recarga de aquíferos, áreas de amortecimento de cheias, terrenos mais suscetíveis à erosão.

Na Figura 3, mostram-se dois tipos de parcelamento do solo: parcelamento tradicional, com arruamento na forma xadrez, sem considerar as características naturais do terreno; parcelamento respeitando a topografia do terreno (arruamento principal acompanhando as curvas de nível) e a drenagem natural das águas (adotando uma área verde no fundo do vale).

Da Figura 4, consta um exemplo de parcelamento do solo com baixo impacto ambiental, comparando-se com um projeto tradicional de parcelamento.

\section{O CENÁRIO INTERNACIONAL}

As ações de gestão ambiental e as leis de proteção de recursos hídricos dependem da história de cada país e refletem as heranças das relações entre sociedade e natureza.
Se compararmos o Brasil com países da Europa, por exemplo, constata-se que a transformação da natureza em espaços socialmente apropriados é recente na maior parte do país. Quando se pretende comparar os

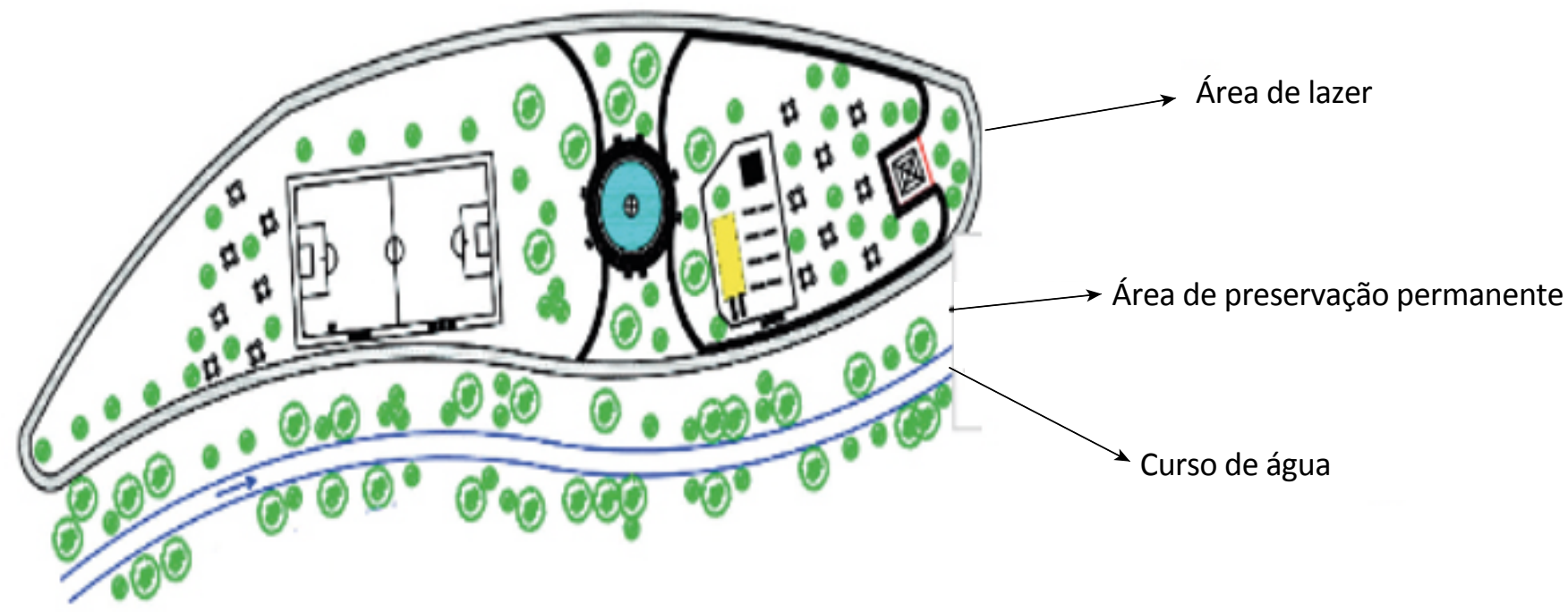

Fonte: adaptado de Carneiro e Miguez (2012).

Figura 2 - Faixa de preservação e área de lazer às margens de um curso de água. 
modelos de legislação e sua aplicação no Brasil com os de outros países, quanto às APPs, observa-se que há características diversas do meio, de legislação ambiental e diferentes necessidades de gestão, que dependem da realidade de cada país, as quais resultam dos processos históricos de uso e ocupação do solo.

Na França, por exemplo, as áreas naturais praticamente desapareceram, em 2010, elas representavam 1,2\% do território (núcleos dos parques nacionais; áreas municipais de proteção da biota, reservas naturais nacionais e regionais na Córsega, reservas biológicas integrais e implementadas). Em outros espaços nacionais, os ambientes foram modificados pelas intervenções humanas profundamente e em um passado distante. Os leitos fluviais na França foram consideravelmente modificados e é difícil encontrar segmentos intocados, exceto em trechos próximos às nascentes ou de montanha. Eles foram transformados para a navegação fluvial, geração de energia hidrelétrica, mineração de depósitos aluviais, drenagem de bacias hidrográficas, proteção contra as inundações, abastecimento de água etc. Estas transformações têm produzido muitas perturbações, nas quais os instrumentos legais têm procurado objetivar na busca de ações de remediação (GASS et al., 2016).

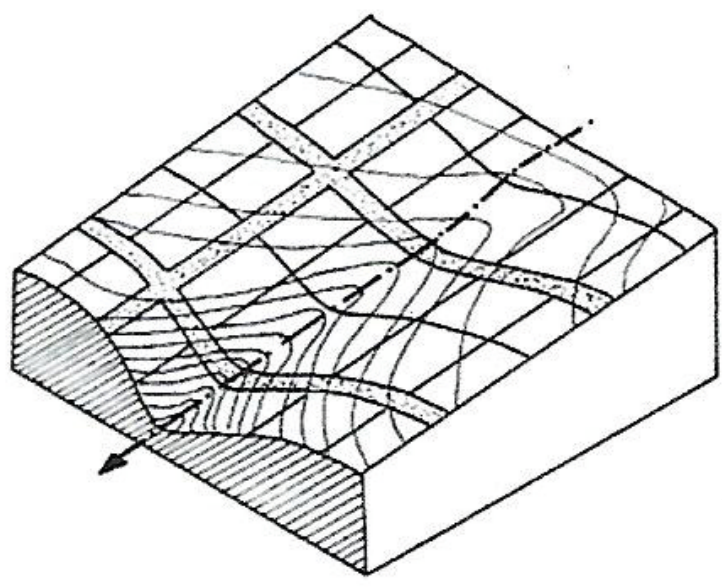

Área livre

Parcelamento tradicional
De acordo com Gass et al. (2016), as faixas de vegetação herbácea ou florestal são definidas pela Lei $\mathrm{n}$ 788 , de 2010 , que obriga os proprietários rurais a estabelecerem sua largura em pelo menos cinco metros. Suas funções semelhantes às de zonas úmidas (regulação do fluxo, purificação da água etc.) são claramente entendidas como uma forma de reduzir os fluxos de poluentes e de sedimentos que vêm das parcelas agrícolas. É a única norma que se impõe nos cursos d'água do espaço nacional.

Embora não exista na França um código florestal que defina limites para faixas de preservação, deve-se considerar que esse país é referência na gestão das águas, atuando fortemente na gestão territorial e de bacias hidrográficas, de forma integrada, visando à proteção dos mananciais.

Segundo Pedroso Júnior et al. (2015), nos Estados Unidos, a regulação das APPs é descentralizada. Assim, ela varia conforme o estado em que a área está localizada, o ente competente para normatizar o uso daquele local e a titulação (pública ou privada) da propriedade em que a APP está inserida. Diante dessa variedade, foi desenvolvida uma série de instrumentos para proteger áreas equivalentes às APPs brasileiras. 
O Committee on Riparian Zone Functioning and Strategies for Management, Water Science and Technology Board do National Research Council dos Estados Unidos estabeleceu algumas estratégias legais de proteção, a serem observadas pelos diferentes entes em diversos contextos (NATIONAL RESEARCH COUNCIL, 2002):

- Exigir identificação e análise de impactos a serem causados, com base em políticas de abrangência nacional e/ou estatal. Embora essa estratégia não se aplique apenas às florestas ripárias, ela é útil para que alternativas menos danosas sejam consideradas quando há intervenção nessas áreas;

- Limitar as atividades que o poder público pode desenvolver em florestas ripárias;

- Regular as atividades em florestas ripárias privadas, resguardando equilíbrio entre os direitos do proprietário e o interesse público;

- Incentivar em termos econômicos e capacitação técnica para a preservação de áreas ripárias, combinados a uma política de educação ambiental;

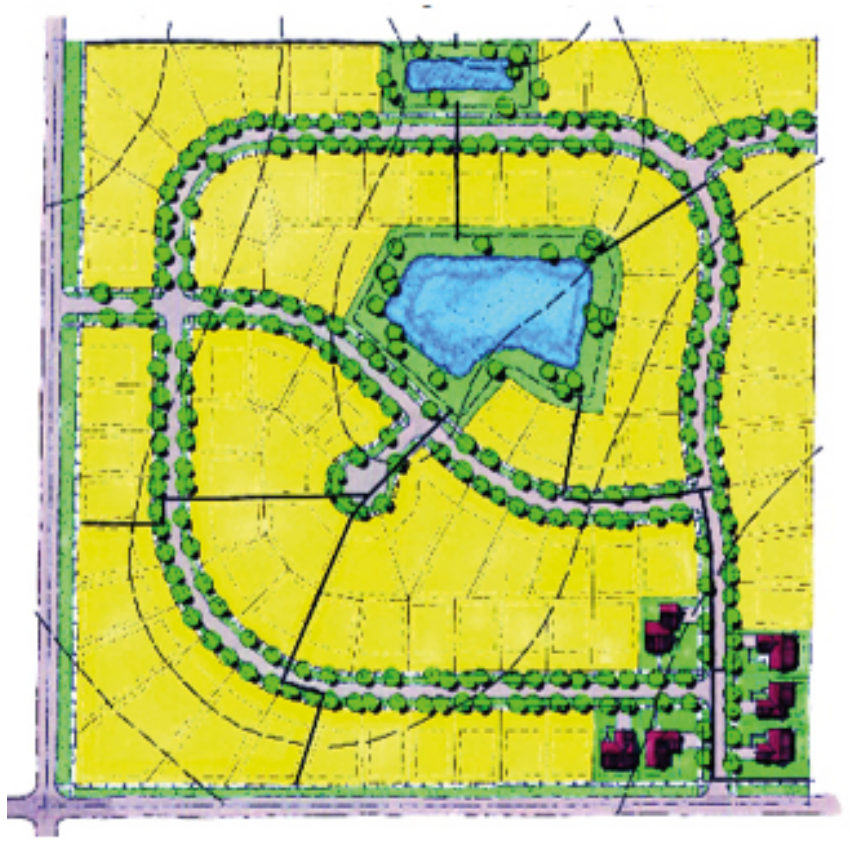

Projeto tradicional de parcelamento do solo
- Comprar (ou receber como doação) áreas privadas pelo poder público. Particularmente, essa estratégia tem sido muito utilizada no contexto urbano para criar corredores verdes (greenways) tanto com objetivos preservacionistas quanto recreativos.

Pedroso Júnior et al. (2015) ressaltam que essas estratégias estão baseadas em instrumentos normativos de abrangência federal, estadual e local. Embora a Federação seja competente para tratar de alguns aspectos específicos da proteção de áreas ripárias, em regra a competência sobre a matéria é dos estados. Porém, tradicionalmente, os estados delegam esse poder para as autoridades locais, de modo que grande parte da normatização dos Estados Unidos sobre a matéria é dotada de pequena abrangência. A maioria dessas normas desencoraja ou proíbe construções próximas aos lagos e cursos de água.

São exemplos de exigências feitas por estados americanos, de acordo com Pedroso Júnior et al. (2015):

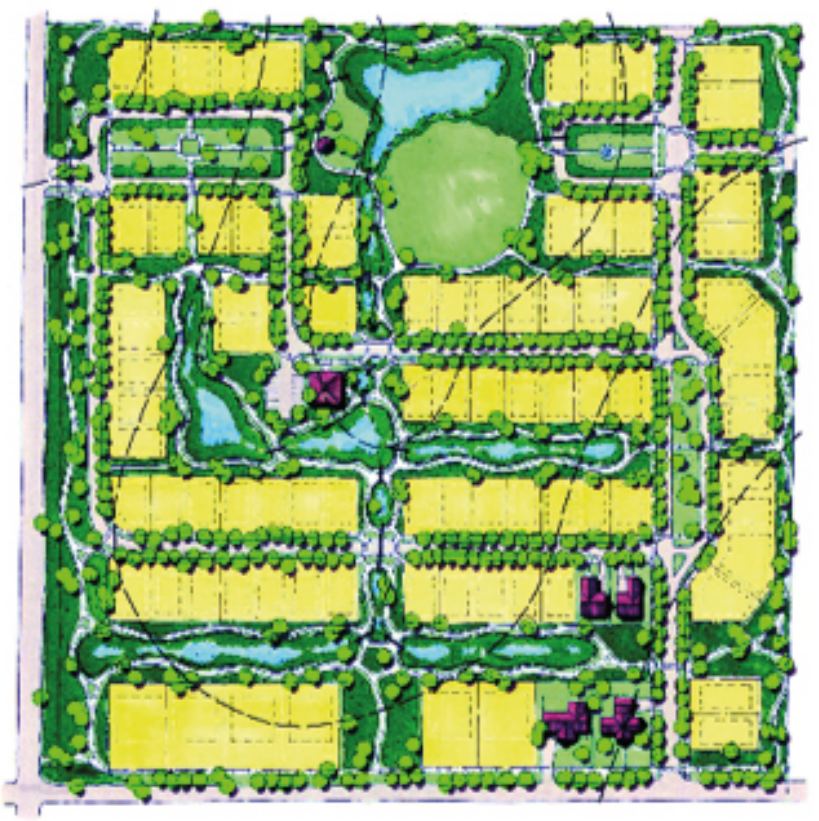

Projeto de parcelamento do solo com baixo impacto

Fonte: CMAP (2003).

Figura 4 - Projeto tradicional de parcelamento e projeto de parcelamento com baixo impacto. 
Massachusetts: as APPs têm uma extensão de cerca de 60 metros medidos a partir de cada margem do rio, entretanto essa largura diminui para 8 metros em determinados municípios urbanizados (como Boston e Chelsea, por exemplo), assim como em áreas densamente desenvolvidas (que assim forem designadas pelo órgão de meio ambiente competente). Além disso, os tipos de atividades e projetos permitidos na área de proteção variam conforme sua localização, a depender dos impactos do projeto e das características naturais locais;

- . New Hampshire: designa como área de proteção especial áreas localizadas até cerca de 80 metros de "águas públicas" (que incluem rios, a costa, e outros corpos de água). Nessas áreas, são proibidas determinadas atividades (como utilização para ferro-velho, por exemplo). Os demais usos urbanos, industriais ou agrícolas devem obedecer a standards mínimos de proteção;

- Maryland: as APPs são classificadas entre áreas intensamente desenvolvidas, áreas desenvolvidas de modo limitado, ou áreas de conservação de recursos. A regulação das atividades a serem autorizadas nesses locais depende desta classificação.

Por causa do papel ecológico fundamental desses ambientes, a sua fragilidade e os serviços ecossistêmicos que prestam à sociedade, a União Europeia ressalta a necessidade de uma avaliação ampla da cobertura ri- beirinha na Europa. Conhecer a sua distribuição pode fornecer a base para uma caracterização abrangente e uma análise ecológica em escala continental, para identificar as principais zonas ripárias, manter a conectividade paisagística, monitorar as tendências de mudança e avaliar os serviços ecossistêmicos que essas zonas podem fornecer (CLERICl et al., 2011).

Clerici et al. (2011) desenvolveram um modelo piloto de zoneamento das áreas ripárias para a Europa continental. Com base nos resultados do modelo, $2 \%$ da Europa continental é vista como áreas ripárias. A alta densidade dessas áreas é encontrada em territórios montanhosos, onde a densa rede hidrográfica e os habitats naturais estendidos criam as condições para a sua abundância. Em áreas simples, a presença de zonas agrícolas é a principal causa da baixa densidade das ripárias e da alta fragmentação. Uma primeira caracterização mostra que uma grande parte das zonas ripárias europeias (cerca de 70\%) está associada ao habitat florestado, enquanto em menor medida às outras formas de vegetação. Esse resultado é importante, uma vez que fornece localização e uma indicação quantitativa de habitats florestais na Europa, que também têm significado ecológico como zonas ripárias.

Estudando a situação de várias cidades do Canadá, Ibrahim e Patrick (2017) concluíram que decisões políticas constituem o fator mais significativo para o planejamento e a gestão das ações de proteção dos recursos hídricos, sendo a capacidade técnica o segundo aspecto mais importante.

\section{LEGISLAÇÃO E ÁREAS DE PRESERVAÇÃO PERMANENTE EM FORTALEZA, CEARÁ}

\section{Aspectos legais}

O Plano Diretor participativo de Fortaleza instituído em 2009 definiu o macrozoneamento da cidade de Fortaleza em duas macrozonas: macrozona de proteção ambiental e macrozona de ocupação urbana. Essa classificação foi reconhecida pela Lei de Uso e Ocupação do Solo (Lei Complementar no 62/2009 e alterações), na qual foi especificada a composição da macrozona de proteção ambiental (FORTALEZA, 2009).

A macrozona de proteção ambiental é constituída de ecossistemas de interesse ambiental, bem como por áreas destinadas à proteção, preservação, recuperação ambiental e ao desenvolvimento de usos e atividades sustentáveis, e é composta das seguintes zonas:

- Zona de preservação ambiental (ZPA), subdividida nas seguintes zonas: faixa de preservação permanente dos recursos hídricos (ZPA 1); faixa de praia (ZPA 2) e Parque Natural Municipal das Dunas de Sabiaguaba (ZPA 3);

- Zona de recuperação ambiental (ZRA); 
- Zona de interesse ambiental (ZIA), subdividida nas seguintes Zonas: ZIA Coco, ZIA Praia do Futuro e ZIA Sabiaguaba.

O Capítulo III da Lei de Uso e Ocupação do Solo trata das normas específicas para ocupação das ZPA. Destaca-se o artigo 103: "Não será permitido o parcelamento do solo, tampouco a edificação, na Zona de Preservação Ambiental (ZPA), sendo permitido apenas o uso indireto dos recursos naturais" (FORTALEZA, 2017). O artigo 103 estabelece que nas áreas que estejam totais ou parcialmente em ZPA não se permite nenhum tipo de construção, até mesmo parcelamento do solo, o que reforça a necessidade de manter esses espaços preservados.

O parágrafo único do artigo 106 da Lei de Uso e Ocupação do Solo estabelece: "A execução de quaisquer obras, planos, atividades ou projetos de atividades públicas ou de interesse social será consoante o art. 8응 da Lei no 12.651/2012 (código florestal)" (FORTALEZA, 2017). O art. 8 do Código Florestal trata da supressão vegetal nas APPs, admitindo: "A intervenção ou a supressão de vegetação nativa em Área de Preservação Permanente somente ocorrerá nas hipóteses de utilidade pública, de interesse social ou de baixo impacto ambiental previstas nesta Lei" (BRASIL, 2012). Ou seja, a Lei de Uso e Ocupação do Solo faz menção ao Código Florestal no que tange à supressão de mata nativa, equiparando as ZPA e APP, admitindo que ambas possuam as mesmas funções ambientais.

Neste contexto, entende-se que as APP dos recursos hídricos do município de Fortaleza estão amparadas pela legislação municipal por meio das ZAP-1. Quando se consideram as diretrizes e gestão dessas áreas, o plano diretor municipal assemelha-se ao Código Florestal brasileiro, no entanto as distâncias e os limites mínimos estabelecidos pela legislação federal para as APP nem sempre são observados na legislação municipal para as ZPA.

A seguir, faz-se uma análise da situação das APP dos recursos hídricos urbanos, no contexto da legislação municipal da cidade de Fortaleza.

\section{Alterações na legislação e as zonas de preservação ambiental de Fortaleza}

O Plano Diretor de Fortaleza sofreu alterações durante sua vigência, sendo a última decorrente da Lei Complementar no 250 , de 3 de julho de 2018, que afetou diretamente as APP dos recursos hídricos, atingindo 18 sub-bacias hidrográficas de Fortaleza (FORTALEZA, 2018). Vários limites de ZPA 1 foram alterados por essa lei complementar.

Utilizando-se os arquivos disponíveis no site da Prefeitura de Fortaleza, e usando a superposição de mapas em programa de SIG, foram determinadas as alterações nas ZPA 1 decorrentes da referida lei complementar.

Antes da vigência da Lei Complementar no 250/2018, o município de Fortaleza possuía 45.459.564,24 $\mathrm{m}^{2}$ de ZPA 1. Com a vigência dessa lei, foram acrescidos $3.701 .792,03 \mathrm{~m}^{2}$ e suprimidos $4.662 .977,37 \mathrm{~m}^{2}$, resultando na redução de $961.185,34 \mathrm{~m}^{2}(2,11 \%)$ de áreas das ZPA 1.

Ressalta-se que a legislação municipal nem sempre observa o Código Florestal na definição das áreas de preservação permanente, tendo estabelecido faixas com larguras inferiores ao mínimo de 30 metros exigido na legislação federal. Além disso, em vários casos, as ZPA 1 não devem corresponder somente aos 30 metros nas margens dos recursos hídricos urbanos, pois as medidas mínimas a serem adotadas devem variar em função das larguras das calhas do leito regular dos cursos d'água, como exige o código florestal, o que não ocorreu em Fortaleza. Assim, o total de APP às margens dos recursos hídricos de Fortaleza, se fosse observada a lei federal, seria bem superior ao que é exigido pela legislação municipal em vigor (Lei Complementar no 250, de 3 de julho de 2018).

Como exemplo de alterações ocorridas nas áreas de preservação dos recursos hídricos de Fortaleza, elaborou-se o mapa constante da Figura 5, no qual é possível observar, na bacia do Rio Cocó, as áreas de ZPA 1 acrescidas, suprimidas e mantidas pela Lei Complementar $n$ ㅇ 250/2018, comparando-se com as áreas anteriores, definidas na Lei de Uso e Ocupação do Solo de Fortaleza (Lei Complementar no 62/2009, alterada pela Lei Complementar $n$ ㅇ 101/2011) (FORTALEZA, 2011). 
Na Bacia do Rio Maranguapinho também foram observadas algumas supressões de áreas de ZPA 1, como indicado na Figura 6.

Vê-se que ocorreram reduções nas APP das duas bacias hidrográficas (indicadas nas legendas com cinza escuro), principalmente nos trechos mais urbanizados.

A fragmentação das ZPA 1 constitui um dos principais problemas, pois as APP de recursos hídricos fragmentadas tornam-se mais vulneráveis à ocupação.

A ocupação de APP é um problema recorrente nas cidades brasileiras densamente urbanizadas.
Ressalta-se que, como no caso de Fortaleza, as legislações municipais que definem as APP nem sempre observam as exigências do código florestal, pois estabelecem faixas com larguras inferiores às exigidas na legislação federal.

Em Fortaleza, muitas áreas das ZPA são ocupadas por assentamentos precários, residências, serviços, indústrias, equipamentos públicos, entre outros. A maioria das ocupações ocorre por edificações e vias, ou seja, essas áreas encontram-se impermeabilizadas, o que influencia diretamente na drenagem das águas pluviais, sendo comum a ocorrência de enchentes.

\section{CONCLUSÕES}

O crescimento das áreas urbanas tem ocorrido, geralmente, de forma desordenada, com a ocupação de áreas que deve- riam ser preservadas, como as margens de recursos hídricos (APP), resultando em diversos problemas ambientais.

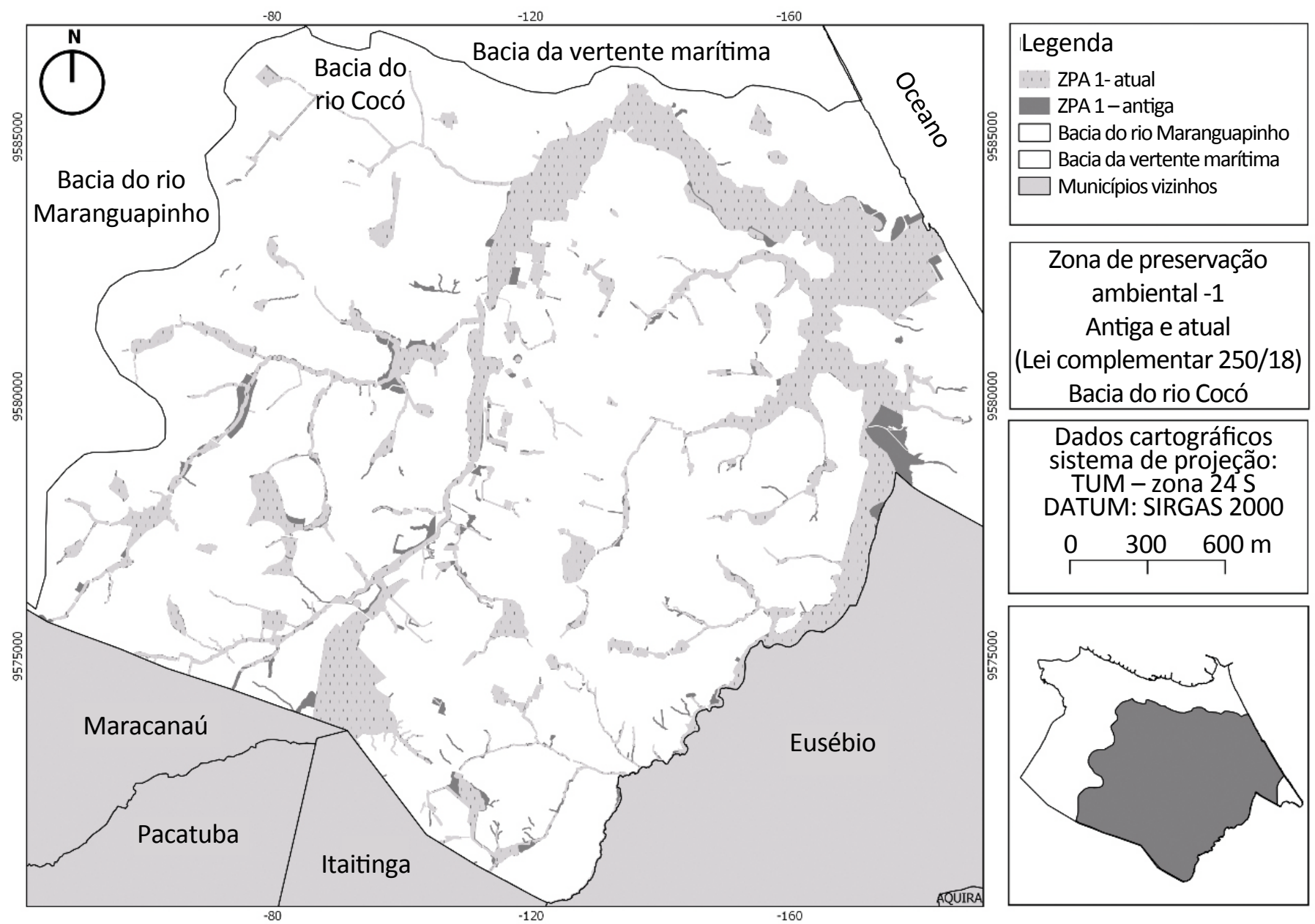

Figura 5 - Zonas de Preservação Ambiental 1 da Bacia do rio Cocó, Fortaleza, Ceará, antes e depois da Lei Complementar no 250/2018. 
É necessário que a ocupação dessas áreas seja controlada, o que ressalta a importância da gestão ambiental e da legislação de controle urbano. As ações de gestão ambiental no município têm grande importância para a proteção dos recursos hídricos. Do mesmo modo, uma legislação de uso e ocupação do solo que tenha como objetivo o uso adequado dos recursos naturais é fundamental para a preser- vação das áreas situadas às margens dos recursos hídricos, consideradas como de preservação permanente.

A legislação municipal de uso e ocupação do solo deve observar as exigências do código florestal, no que se refere às APP, no entanto isso nem sempre acontece, como no caso da legislação de Fortaleza.

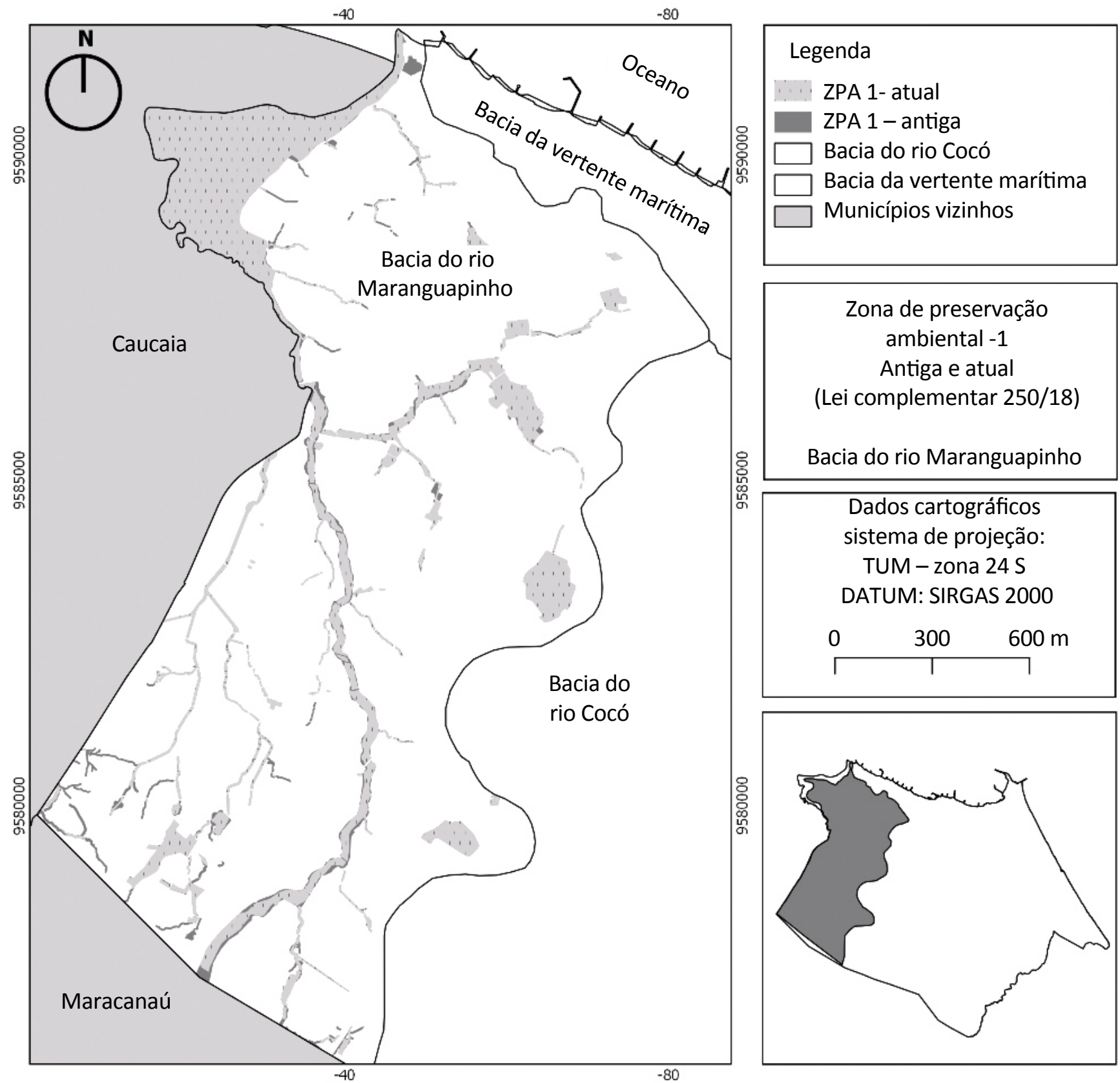

Figura 6 - Zonas de Preservação Ambiental 1 da Bacia do rio Maranguapinho, Fortaleza, Ceará, antes e depois da Lei Complementar no 250/2018. 
A legislação que trata das ZPA 1 em Fortaleza é menos restritiva que o código florestal, definindo, em muitos casos, faixas de preservação com menos de $\mathbf{3 0}$ metros às margens dos recursos hídricos, mínimo exigido pela lei federal.

Alterações efetuadas na Lei de Uso e Ocupação do Solo têm resultado na redução das áreas de preservação.
As últimas modificações, definidas na Lei Complementar no 250/2018, resultaram na redução de $961.185,34 \mathrm{~m}^{2}$ $(2,11 \%)$ de áreas inseridas nas ZPA 1 de Fortaleza.

Além disso, tem ocorrido a ocupação das áreas consideradas como de preservação pela legislação municipal, o que tem ocasionado sérios problemas de drenagem, com graves consequências para a população.

\section{REFERÊNCIAS}

AITHER. Advisors in Water Policy Management. A Guide to managing water for the environment (a framing paper for the high level panel on water). Camberra: Australian Water Partnership, 2018.

BRASIL. Constituição da República Federativa do Brasil. Diário Oficial da União, Brasília, 5 out. 1988.

BRASIL. Lei no 4.771, de 25 de maio de 2012. Institui o Código Florestal Brasileiro. Diário Oficial da União, Brasília, 28 maio 2012.

BRASIL. Lei no 6.938, de 31 de agosto de 1981. Institui a Política Nacional do Meio Ambiente. Diário Oficial da União, Brasília, 2 set. 1981.

BRASIL. Lei no 9.433, de 8 de janeiro de 1997. Institui a Política Nacional de Recursos Hídricos. Diário Oficial da União, Brasília, 9 jan. 1997.

BRASIL. Lei no 10.257, de 10 de julho de 2001. Estabelece diretrizes gerais da política urbana (Estatuto da Cidade). Diário Oficial da União, Brasília, 11 jul. 2001.

BRASIL. Lei no 13.683, de 19 de junho de 2018. Institui as diretrizes da Política Nacional de Mobilidade Urbana (Estatuto da Metrópole). Diário Oficial da União, Brasília, 20 jun. 2018.

CAMPAGNOLO, K.; SILVEIRA, G.L. da; MIOLA, A.; SILVA, R.L.L. Área de Preservação Permanente de um rio e análise da legislação de proteção da vegetação nativa. Ciência Florestal, Santa Maria, v. 27, n. 3, p. 831-842, 2017. http://dx.doi. org/10.5902/1980509828633

CARNEIRO, P.R.F.; CARDOSO, A.L.; AZEVEDO, J.P.S. O planejamento do uso do solo urbano e a gestão de bacias hidrográficas: o caso da bacia dos rios Iguaçu / Sarapuí na Baixada Fluminense. Cadernos Metrópole, n. 19, p. 165-190, 2008.

CARNEIRO, P.R.F.; MIGUEZ, M.G. A Flood Control Approach Integrated with a Sustainable Land Use Planning in Metropolitan Regions. In: APPIAH-OPOKU, S. (org.). Environmental Land Use Planning. Rijeka, Croácia: InTech, 2012. Cap. 7.

CLERICI, N.; WEISSTEINER, C.J.; PARACCHINI, M.L.; STROBOL, P. Riparian zones: where green and blue networks meet. Pan-European zonation modeling based on remote sensing and GIS. Ispra (VA), Itália: JRC Scientific and Technical Reports, 2011.

CHICAGO METROPOLITAN AGENCY FOR PLANNING (CMAP). Conservation Design Forum. Elmhurst: CMAP, 2003. Disponível em: <https://www.cmap.illinois.gov/about/2040/supporting-materials/process-archive/strategy-papers/ conservation-design/principles-and-practices>. Acesso em: 23 ago. 1999. 
CREMONEZ, F.E.; CREMONEZ, P.A.; FEROLDI, M.; CAMARGO, M.P.; KLAJN, F.F.; FEIDEN, A. A Avaliação de impacto ambiental: metodologias aplicadas no Brasil. Monografias Ambientais, Santa Maria, v. 13, n. 5, p. 3821-3830, 2014. http://dx.doi.org/10.5902/2236130814689

DÍAZ-PASCACIO, E.; ORTEGA-ARGUETA, A.; CASTILO-UZCANCA, M.M.; RAMÍREZ-MARCIAL, N. Influence of land use on the riparian zone condition along an urban-rural gradient on the Sabinal River, Mexico. Botanical Sciences, v. 96, n. 2, p. 180-1999, 2018. https://doi.org/10.17129/botsci.1858

FORTALEZA. Lei Complementar no 62, de 2 de fevereiro de 2009. Institui o Plano Diretor Participativo do Município de Fortaleza. Diário Oficial do Município, Fortaleza, 13 mar. 2009.

FORTALEZA. Lei Complementar no 101, de 30 de dezembro de 2011. Altera a lei que institui o plano diretor participativo do Município de Fortaleza. Diário Oficial do Município, Fortaleza, 23 jan. 2012.

FORTALEZA. Lei Complementar no 236, de 11 de agosto de 2017. Dispõe sobre o uso e ocupação do solo do Município de Fortaleza. Diário Oficial do Município, Fortaleza, 24 ago. 2017.

FORTALEZA. Lei Complementar $n$ o 250, de 3 de julho de 2018. Altera a lei que institui o plano diretor participativo do Município de Fortaleza. Diário Oficial do Município, Fortaleza, 31 jul. 2018.

GASPAR, S.; KLINK, J. Integração regional e gestão dos recursos hídricos: O Plano da Bacia do Alto Tietê e os organismos da articulação regional do grande ABC. Revista Brasileira de Ciências Ambientais, n. 16, p. 14-19, 2008.

GASS, S.L.B.; VERDUM, R.; CORBONNOIS, J.; LAURENT, F. Áreas de preservação permanente no Brasil e na França: um comparativo. Revista Franco-Brasileira de Geografia Confins, v. 27, n. 27, 2016. https://doi.org/10.4000/confins.10829

Global Water Partnership. The Need for an Integrated Approach. 2017. Disponível em: <https://www.gwp.org/en/ About/why/the-need-for-an-integrated-approach>. Acesso em: 23 jul. 2019.

GOVERNO DO ESPÍRITO SANTO. Manual de orientação à aprovação de parcelamento do solo para fins urbanos. Vitória: Secretaria de Estado de Economia e Planejamento do Estado do Espírito Santo, 2006.

IBRAHIM, A.A.; PATRICK, R.J. Source Water Protection Planning and Management in Metropolitan Canada: A Preliminary Assessment. Water, v. 9, n. 7, p. 497-511, 2017. https://doi.org/10.3390/w9070497

KAUSHAL, S.S.; MCDOWELL, W.H.; WOLLHEIM, W.M.; JOHNSON, T.A.N.; MAYER, P.M.; BELT, K.T.; PENNINO, M.J. Urban Evolution: The Role of Water. Water, v. 7, p. 4063-4087, 2015. https://doi.org/10.3390/w7084063

KUMAR, A.; KUMAR, S.; KHOSLA, M. Issues of environmental management of water resource development projects. International Journal of Scientific Engineering and Applied Science, v. 2, n. 3, p. 99-110, 2016.

KUSLER, J. Protecting and restoring riparian areas. Windham: Association of State Wetland Managers, 2016.

MCGRANE, S.J. Impacts of urbanization on hydrological and water quality dynamics, and urban water management: a review. Hydrological Sciences Journal, v. 61, n. 13, p. 2295-2311, 2016. https://doi.org/10.1080 /02626667.2015.1128084

MINISTÉRIO PÚBLICO DE SANTA CATARINA (MPSC). Guia do parcelamento do solo urbano: perguntas e respostas, consultas e modelos. Florianópolis: MPSC, 2010.

MOTA, S. Gestão Ambiental de Recursos Hídricos. 4ạ ed. Rio de Janeiro: Abes, 2019.

MOTA, S. Introdução à Engenharia Ambiental. 6a ed. Rio de Janeiro: Abes, 2016.

MOTA, S. Urbanização e Meio Ambiente. 4a ed. Rio de Janeiro: Abes, 2011. 
NATIONAL RESEARCH COUNCIL. Riparian areas: functions and strategies for management. Washington, D.C.: National Academy Press, 2002.

NOLASCO, A.; SILVA FILHO, D.F. da. Métodos e Instrumentos de Gestão Ambiental Urbana: conceitos básicos e aplicações. 2010. Disponível em: <http://cmq.esalq.usp.br/wiki/lib/exe/fetch.php?media=publico:syllabvs:Icf0300:aula3a_2010. pdf>. Acesso em: 26 ago. 2019.

PALAVIZINI, R. Planejamento e gestão transdisciplinar do ambiente e do território. Uma perspectiva aos processos de planejamento e gestão social no Brasil. Revista Brasileira de Ciências Ambientais, n. 26, p. 62-74, 2012.

PEDROSO JÚNIOR, N.N.; STEINMETZ, S.; SANTOS, A.C.; CRUZ, J.C. (orgs.). Estratégia Regional para Áreas de Preservação Permanente Urbanas. Relatório Final Projeto APPs Urbanas. São Paulo: Faculdade Getúlio Vargas / Centro de Pesquisa Jurídica e Aplicada, 2015.

PERES, R.B.; SILVA, R.S. da. Interfaces da gestão ambiental urbana e gestão regional: análise da relação entre Planos Diretores Municipais e Planos de Bacia Hidrográfica. Revista Brasileira de Gestão Urbana, v. 5, n. 2, p. 13-25, 2013. https://doi.org/10.7213/urbe.05.002.SE01

PHILIPPI JR., A.; BRUNA, G.C. Política e Gestão Ambiental. In: PHILIPPI JR., A.; ROMÉRO, M.A.; BRUNA, G.C. (orgs.). Curso de Gestão Ambiental. 2a ed. Barueri: Manole, 2013.

PIZELLA, D.G. A relação entre Planos Diretores Municipais e Planos de Bacias Hidrográficas na gestão hídrica. Ambiente e Água, v. 10, n. 3, p. 635-645, 2015. https://doi.org/10.4136/ambi-agua.1394

RANDOLPH, J. Environmental land use planning and management. Washington, D.C.: Island Press, 2011.

RIEMANN, K.; McGIBBON, D.C.; GESTER, K; SCHEIBERT, S.; HOOSAIN, M.; HAY, E.P. Water resource protection: research report. A review of the state-of-the-art and research and development needs for South Africa. Gezina, África do Sul: Water Research Commission, 2017.

SANTOS, E.F. O papel dos municípios na proteção dos recursos hídricos. Revista Brasileira de Direito Constitucional, n. 18, p. 105-123, 2011.

SÁ-SILVA, R.J.; ALMEIDA, D.A.; GUINDANI, J.F. Pesquisa documental: pistas teóricas e metodológicas. Revista Brasileira de História \& Ciências Sociais, v. 1, n. 1, p. 1-15, 2009.

SILVA, R.F. da; SANTOS, V.A.; GALDINO, S.M.G. Análise dos impactos ambientais da urbanização sobre os recursos hídricos na sub-bacia do Córrego Vargem Grande em Montes Claros-MG. Caderno de Geografia, v. 26, n. 47, 2016. https://doi.org/10.5752/P.2318-2962.2016v26n47p966

SUN, G.; CALDWEEL, P. Impacts of urbanization on stream water quantity and quality in The United States. Water Resources IMPACT, v. 17, n. 1, p. 17-20, 2015.

WANG, Y.; HO, J.K.; LU, J. Water resources and environmental management. Journal of Water and Climate Change, v. 10, n. 2, p. 3-4, 2019. https://doi.org/10.2166/wcc.2019.000

ZANDER, K.; DARÓS, T.; FERNANDES, V.; ANDREOLI, C. Código florestal brasileiro: Alguns esclarecimentos sobre embate político inerente a sua reforma. Revista Brasileira de Ciências Ambientais, n. 16, p. 44-56, 2010.

ZHANG, H.; JIN, G.; YU, Y. Review of River Basin Water Resource Management in China. Water, v. 10, n. 4, p. 425-439, 2018. https://doi.org/10.3390/w10040425 